Вестник Новосибирского государственного педагогического университета

(C) Р. И. Айзман, А. Д. Герасёв, О. Айзман, Г. И. Крашенинина, Е. М. Трофимович

DOI: $10.15293 / 2226-3365.1805 .16$

УДК 612+59

ФИЗИОЛОГО-ГИГИЕНИЧЕСКОЕ ОБОСНОВАНИЕ НОРМЫ КАЛИЯ В ПИТЬЕВОЙ ВОДЕ: НАУЧНО-ПРАКТИЧЕСКОЕ ЗНАЧЕНИЕ

\author{
Р. И. Айзман, А. Д. Герасёв (Новосибирск, Россия), О. Айзман (Стокгольм, Швеция) \\ Г. И. Крашенинина, Е. М. Трофимович (Новосибирск, Россия)
}

Проблема и цель. В настоящее время отсутствуют физиолого-гигиенические исследования по обоснованию оптимальной (ОГН) и допустимой (ДГН) гигиенической нормы калия в питьевой воде. Установленная директивой 98/83ЕС Европейского сообщества норма без экспериментального обоснования делает бездоказательным преподавание данного раздела в образовательных курсах «Физиология водно-солевого обмена» и «Гигиена водоснабжения». Это и послужило иелью настоящей работы: рассмотреть физиологию метаболизма калия в организме, на основании чего экспериментально определить его гигиенические нормы в питьевой воде.

Методология. Для обоснования гигиенической нормы содержания калия в питьевой воде использован физиолого-гигиенический подход, основанный на теоретическом и экспериментальном изучении гомеостаза калия в организме высших животных и человека, а также на анализе физиологических реакций организма на длительные дозозависимые воздействия нагрузками калия. Это позволило интегрировать результаты исследования в систему нормативов данного катиона в питьевой воде. Такой физиолого-гигиенический подход к решению проблемы стал возможен благодаря длительному сотрудничеству исследователей двух научных школ г. Новосибирска:

Айзман Роман Иделевич - доктор биологических наук, профессор, заслуженный деятель науки РФ, заведующий кафедрой анатомии, физиологии и безопасности жизнедеятельности, Новосибирский государственный педагогический университет, главный научный сотрудник, Новосибирский НИИ гигиены Роспотребнадзора.

E-mail: aizman.roman@yandex.ru

Герасёв Алексей Дмитриевич - доктор биологических наук, профессор, ректор, Новосибирский государственный педагогический университет.

E-mail: ad-gerasev@yandex.ru

Айзман Олег - Ph.D., M.D., Департамент анестезиологии и интенсивной терапии, Каролинский институт (Стокгольм, Швеция).

E-mail: ol.aizman@gmail.com

Крашенинина Галина Ивановна - доктор медицинских наук, профессор кафедры гигиены и экологии, Новосибирский государственный медицинский университет, главный научный сотрудник, Новосибирский НИИ гигиены Роспотребнадзора.

E-mail: ngi@niig.su

Трофимович Евгений Михайлович - доктор медицинских наук, профессор кафедры анатомии, физиологии и безопасности жизнедеятельности, Новосибирский государственный педагогический университет.

E-mail: aph@nspu.ru 
Вестник Новосибирского государственного педагогического университета

2018, том 8, № 5

www.vestnik.nspu.ru

ISSN 2226-3365

физиологов НГПУ и спеииалистов НИИ гигиены, научные разработки которых в области физиологии регулячии гомеостаза калия и гигиены водоснабжения получили мировое признание.

Результаты. Показано, что регуляиия баланса калия в организме обеспечивается как прямым действием избытка катиона на почки в случае гиперкалиемии, так и рефлекторным механизмом, который включается при всасывании калия из пищеварительного тракта. Заключение базируется на экспериментальных данных о том, что калийрегулирующий рефлекс представлен селективными рецепторами печени, афферентными путями в составе блуждающих нервов, гипоталамическими иентрами и гормонами (ренин-ангиотензин-альдостероновой системой, вазопрессином, инсулином), вызывающими изменение функций основного гомеостатического органа - почек и тканевых калиевых депо (скелетных мыши и печени).

Во второй части описаны результаты 9-месячного хронического эксперимента на крысах, получавщих питьевую воду с разной концентрацией калия и ее влияние на функиию почек. Показано, что концентрация катиона в воде 5,0 мг/дм не вызывала изменений почечного ответа на водные и калиевые нагрузки по сравнению с контролем (концентрация калия в питьевой воде $1,0 \pm 0,2$ мг/ м $\left.^{3}\right)$, тогда как вода с содержанием калия 50 мг/дм ${ }^{3}$ приводила к напряжению механизмов регуляции ионного баланса по сравнению с контролем, что выражалось в увеличении экскреции катионов калия и натрия после водной нагрузки и снижении их выведения после калиевой нагрузки.

Заключение. Полученные данные позволяют заключить, что гигиеническим оптимумом

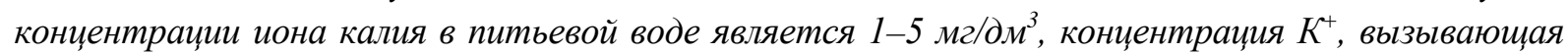

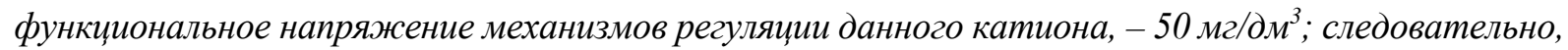
диапазон допустимой гигиенической нормы калия в питьевой воде составляет 0,8-12,5 мг/дм.

Ключевые слова: регуляция гомеостаза калия; функция почек; калиевые нагрузки; концентрачия калия в питьевой воде.

\section{Постановка проблемы}

Калий, являясь основным внутриклеточным катионом, играет важную роль в осуществлении многих физиологических процессов: делении клеток, синтезе белков, активности ферментов, регуляции объема и кислотного-щелочного равновесия клеток, формировании электрического потенциала клеточных мембран и т. д. В раннем возрасте организм нуждается в сохранении калия в большей степени, чем во взрослом, поскольку катион $K^{+}$ нужен для роста и развития [1-5].

Калий присутствует в окружающей среде в виде изотопов: стабильных ${ }^{39} K_{19}-$ $93,08 \%,{ }^{41} K_{19}-6,91 \%$ и радиоактивного

\footnotetext{
1 Человек. Медико-биологические данные. Доклад рабочей группы комитета II МКРЗ по условному человеку. - М.: Медицина, 1977.
}

${ }^{40} K_{19}-0,0110-0,0119 \%$. Из всей группы витальных катионов калий растворяется в воде наиболее активно: $\mathrm{K}^{+}>\mathrm{Na}^{+}>\mathrm{Ca}^{2+}>\mathrm{Mg}^{2+1}$. Однако его концентрация в воде питьевых источников часто бывает низкая в значительной степени вследствие интенсивного его поглощения объектами биоценоза. Высокие концентрации калия в воде наблюдаются реже, в основном в водных источниках, вовлеченных в процессы техногенеза, например ${ }^{2}$, в воде питьевых источников в районах разработки калийных месторождений, размещения золошлакоотвалов теплоэлектростанций и производства калийных месторождений, где он может достигать десятков мг/дм³.

\footnotetext{
${ }^{2}$ Красовский Г. Н., Егорова Н. А. Методология выбора оценочных показателей для гигиенического мониторинга водных объектов // Гигиена и санитария. 1994. - № 6. - C. 5-7.
} 
В воде калий может образовывать минеральные соли: бикарбонат $\left(\mathrm{KHCO}_{3}\right)$, хлорид $(\mathrm{KCl})$, редко сульфат $\left(\mathrm{K}_{2} \mathrm{SO}_{4}\right)$. Скорость образования соединений калия в воде выше, чем натрия ${ }^{3}$. Организм получает калий с пищей и питьевой водой. Поступление калия в организм человека с питьевой водой происходит в ионной форме, а с продуктами питания - в связанной форме ${ }^{4}$.

В отношении многих макро- и микроэлементов, поступающих в организм с питьевой водой, (например, $\mathrm{Na}^{+}, \mathrm{Ca}^{2+}, \mathrm{Mg}^{2+}$ и других) определены пределы концентраций, понижение или повышение которых вызывает физиологические сдвиги или патологические состояния [6-9], поскольку ионизированные минералы питьевой воды имеют высокие показатели физиологической активности, биологической доступности и всасывания [10-12].

В то же время относительно потребления калия организмом научно-экспериментальных доказательств обоснования оптимальной и допустимой гигиенической нормы катиона в питьевой воде до настоящего времени нет, что заставляет использовать директиву 98/83ЕС Европейского сообщества. Это, в свою очередь, делает схоластическим процесс преподавания данной темы в разделах «Физиология водно-солевого баланса» и «Гигиена водоснабжения» таких важных медико-биологических дисциплин, как «Физиология» и «Гигиена», поэтому актуальность физиолого-гигиенического анализа влияния различных концентраций калия в питьевой воде при длительном ее потреблении для установления соответствующей гигиенической нормы становится важной задачей не только для науки, но и для преподавания.

\footnotetext{
${ }^{3}$ Красовский Г. Н., Егорова Н. А. Методология выбора оценочных показателей для гигиенического мониторинга водных объектов // Гигиена и санитария. 1994. - № 6. - С. 5-7.
}

Цель настоящей работы: рассмотреть физиологию метаболизма калия в организме, на основании чего экспериментально обосновать его гигиенические нормы в питьевой воде.

\section{Методология исследования}

Для обоснования гигиенической нормы содержания калия в питьевой воде использован физиолого-гигиенический подход, основанный на теоретическом и экспериментальном изучении гомеостаза калия в организме высших животных и человека, а также на анализе физиологических реакций организма на длительные дозозависимые воздействия нагрузками калия. Это позволило интегрировать результаты исследования в систему нормативов данного катиона в питьевой воде. Такой физиолого-гигиенический подход к решению проблемы стал возможен благодаря длительному сотрудничеству исследователей научных школ г. Новосибирска: физиологов НГПУ и специалистов НИИ гигиены, научные разработки которых в области физиологии регуляции гомеостаза калия и гигиены водоснабжения получили мировое признание.

\section{Результаты исследования}

В организме калий содержится главным образом внутриклеточно и находится в связанной форме, а в межклеточной и сосудистой жидкостях он присутствует в обменной ионной форме [4; 5]. По скорости обмена калия между клеткой и внеклеточной жидкостью органы делятся на три группы: почки, легкие, ки-

\footnotetext{
${ }^{4}$ Трофимович Е. М., Айзман Р. И., Крашенинина Г. И., Герасев А. Д. Обмен калия и его гигиеническое значение. - Новосибирск: Изд-во НГПУ, 2004. - 40 с.
} 
Вестник Новосибирского государственного педагогического университета

шечник > печень, селезенка, мышцы > эритроциты, ткань мозга, кости ${ }^{5}$ При суточном балансе поступления и выведения калия из организма на уровне 0,75-1,5мг/кг он концентрируется во внутриклеточном секторе в объеме 3500 ммоль (98 \% от поступившего), оставаясь во внеклеточном секторе в количестве лишь около 70 ммоль (2\%). В клетках основное количество $\mathrm{K}^{+}$связывается с белками, углеводами, креатинином и фосфорорганическими веществами [13]. При стандартном рационе питания суточное потребление калия человеком массой тела 70 кг составляет в среднем 3,3 г (1,43-6,54). У детей 8-12 лет поступление калия в организм меньше: 3,0 г/сут (1,9-3,3 г). Калий выделяется из организма преимущественно с мочой - 2,8 (1,08-4,91) г/сут, значительно меньше с фекалиями -
0,36 г/сут, и потом - 0,13 г/сут в покое 6 . Баланс между уровнем поступления в организм калия и его выведением называется внешним контуром регуляции, а распределение катиона между внутри- и внеклеточным секторами характеризует внутренний контур регуляции (рис. 1) [2;14].

Содержание калия в организме имеет зависимость также от возраста, мышечной массы и пола людей. У мужчин в возрасте 20 лет содержание калия в организме составляет 2,2 г/кг, а у женщин такого же возраста 1,54 г/кг. У мальчиков содержание калия в организме выражается зависимостью:

$$
K^{+}=8 \times T-13,5 \Gamma( \pm 10,7 \text { г }),
$$

у девочек: $K^{+}=4,7 \times T+10,2$ г $( \pm 6,2$ г), где $T-$ возраст $^{7}$.

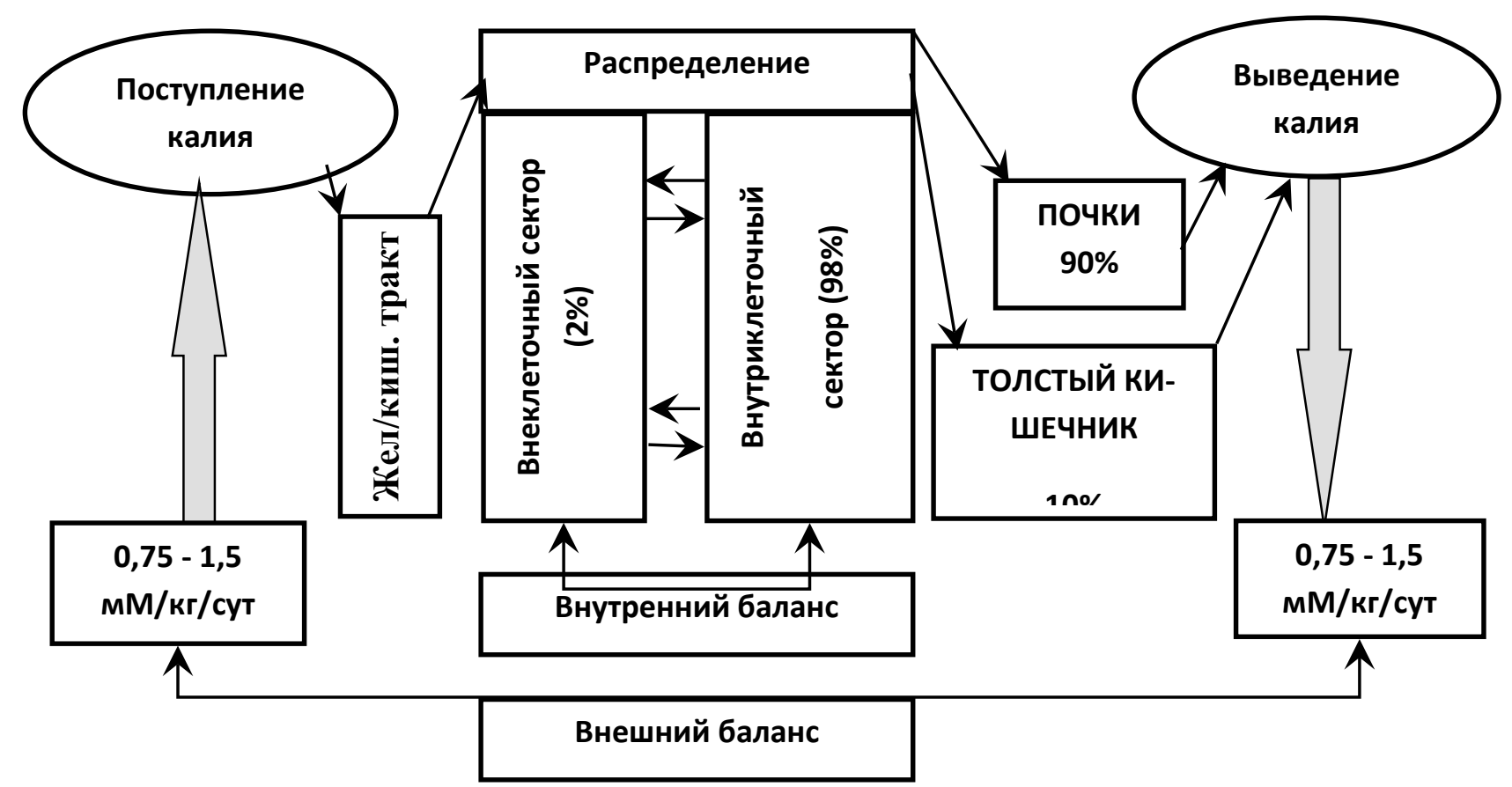

Puc. 1. Схема внешнего и внутреннего контуров регуляции баланса калия

Fig. 1. Scheme of external and internal contours of potassium balance regulation

\footnotetext{
5 Титов В. Н. Натрий плазмы крови // Клиническая лабораторная диагностика. - 1996. - № 3. - С. 3-7.

${ }^{6}$ Трофимович Е. М., Айзман Р. И., Крашенинина Г. И., Герасев А. Д. Обмен калия и его гигиеническое значение. - Новосибирск: Изд-во НГПУ, 2004. - 40 с.
}
7 Человек. Медико-биологические данные. Доклад ра- бочей группы комитета II МКРЗ по условному чело- веку. - М.: Медицина, 1977.


У детей первого года жизни содержание $K^{+}$в организме зависит от питания. В женском молоке через две недели лактации концентрация калия составляет 37-63 мг/100 мл.

Общепринятым показателем, характеризующим калиевый гомеостаз человека, является концентрация калия в плазме в пределах 3,8-4,8 ммоль/л. В слюне концентрация $K^{+}$ находится на уровне плазмы ${ }^{8}$.

Регуляция процесса обмена калия в организме связана с общей системой метаболизма питьевой воды ${ }^{9}$ [13-14]. Калий питьевой воды и пищи в желудочно-кишечном тракте переходит в ионную форму и начинает абсорбироваться в кишечнике, главным образом в толстом отделе [15; 16].

Концентрация ионной формы калия в жидкости тонкого кишечника невелика и составляет всего 6-15 ммоль/л. В желудке и тонком кишечнике калий всасывается быстрее катионов $\mathrm{Na}^{+}$и $\mathrm{Ca}^{2+}$, а по скорости абсорбции уступает только воде. Этот процесс протекает более активно в молодом возрасте [15]. В толстом кишечнике процессы абсорбции и секреции калия сопряжены и концентрация катиона в полости кишки достигает 90 ммоль/л. Это обусловлено тем, что большая часть жидкости абсорбируется в выше лежащих отделах кишечника. Абсорбция калия осуществляется с помощью калий-зависимых АТФаз, расположенных в апикальной части клеток дистального отдела толстого кишечника $\left(H^{+}, K^{+}\right.$-АТФазы и $\mathrm{Na}^{+}$- независимой $\mathrm{K}^{+}$-АТФазы). Секреция калия из крови в кишечник обеспечивается с участием специальных белков: $\mathrm{Na}^{+}, \mathrm{K}^{+}-$ АТФазы и $\mathrm{Na}^{+}, \mathrm{K}^{+}$, 2Cl-транспортера, локализованных на базолатеральной мембране клеток дистального отдела толстого кишечника

${ }^{8}$ Титов В. Н. Натрий плазмы крови // Клиническая лабораторная диагностика. - 1996. - № 3. - С. 3-7.

${ }^{9}$ Трофимович Е. М. Метаболизм питьевой воды. Гигиенический аспект // Методологические проблемы
[1; 4; 16] и активируется относительно недавно открытым семейством белков FXYD, среди которых большую роль придают CHIF [17; 18]. После переноса иона калия через базолатеральную мембрану происходит увеличение его концентрации в клетке. Последующая секреция $K^{+}$осуществляется через калиевые каналы в апикальной мембране клеток. Процесс секреции калия увеличивается под влиянием альдостерона, глюкокортикоидов, норадреналина, простагландинов, а также в условиях диеты, высоко обогащённой калием $[4 ; 13 ; 14 ; 17 ; 18]$. Менее изучена пока регуляция процесса абсорбции калия. Известно только, что гормон соматостатин, $\beta$-агонисты и нейропептид $-Y$ увеличивают абсорбцию воды и электролитов в кишечнике [2; 13; 16].

Сдвиги гомеостаза калия в организме проявляются в направлении отрицательного и положительного балансов, приводящих к состояниям гипо- и гиперкалиемии. Гипокалиемия (гипокалиплазмия), или снижение калия в плазме ниже 3,5 ммоль/л и в моче ниже 50 ммоль/сут возникает, например, при активном переходе $K^{+}$в клетки, использовании мочегонных препаратов, гиперальдостеронизме и некоторых других нарушениях, в том числе, заболеваниях почек [20; 21].

Состояние хронической гипокалиемии клинически характеризуется усталостью, апатией, астенией, мышечной слабостью, сонливостью, парезами кишечника, парестезиями, тахикардией и аритмиями, сопровождающимися метаболическим алкалозом. На ЭКГ в этом случае отмечается удлинение интервала $Q T$, уплощение зубца $T$ и наличие зубца $U$,

изучения, оценки и регламентации химического загрязнения окружающей среды и его влияния на здоровье населения: материалы пленума. - М., 2015. C. 428-433. 
снижение сегмента ST, желудочковые аритмии ${ }^{10}[21]$.

При возникновении дефицита калия в организме в первую очередь наступает уменьшение его концентрации во внеклеточной жидкости, с последующим восполнением за счет депонированной формы катиона.

Содержание калия в организме влияет на секрецию соляной кислоты в желудке. При снижении концентрации калия в клетках слизистой оболочки желудка на 2,5 \% наблюдается прекращение секреции соляной кислоты, поскольку секреция $H^{+}$сопряжена с абсорбцией $K^{+}$в желудке с участием $H^{+}-K^{+}$- АТФазы [22; 23].

Гиперкалиемия (гиперкалиплазмия) характеризуется повышением уровня $K^{+}$в плазме крови более 5,5 ммоль/л. Причинами метаболической гиперкалиемии могут быть факторы, способствующие выходу калия из клеток: гемолиз, некрозы тканей, ацидоз, задержка калия в организме в связи с недостаточным его выведением почками и толстым кишечником, почечной недостаточностью, и реже с высокой концентрацией калия в питьевой воде. Развитию гиперкалиемии при ацидозе способствует также одновременное уменьшение секреции калия в дистальном отделе нефрона. Гиперкалиемия может сопровождаться метаболическим ацидозом ${ }^{11}$ [21; 22]. При избытке $K^{+}$в организме происходит его депонирование в печени и мышцах, где он связывается, главным образом, с гликогеном [24].

В норме при всасывании калия из пищеварительной системы происходит увеличение его концентрации только в системе воротной вены и печени. Эти сдвиги концентрации $K^{+}$ воспринимаются калий-чувствительными рецепторами печени, нервные импульсы от которых по блуждающим нервам поступают в

\footnotetext{
10 Титов В. Н. Натрий плазмы крови // Клиническая ла-
} бораторная диагностика. - 1996. - № 3. - С. 3-7. центральную нервную систему и гипоталамус, где предполагается наличие калийрегулирующего центра $[13 ; 14 ; 16 ; 25 ; 26]$. Эфферентное звено регуляции гомеостаза иона калия находится под контролем вазопрессина (АДГ), адренокортикотропина (АКТГ), альдостерона и, возможно, еще других, пока не установленных гормонов, увеличивающих экскрецию калия основным эффекторным органом - почками [13; 14; 19].

Ренальная экскреция калия является результатом сочетания процессов фильтрации, реабсорбции и секреции катиона в нефронах. Установлено, что процесс клубочковой фильтрации мало влияет на экскрецию катиона калия и лишь снижение скорости клубочковой фильтрации более, чем на $25 \%$ от взрослой нормы приводит к снижению выведения катиона с мочой.

Ионы калия беспрепятственно фильтруются в боуменову капсулу нефрона, поэтому содержание калия в первичном фильтрате практически равно таковому в плазме крови (с учетом различий в содержании белка). Далее около 95-98 \% от профильтровавшегося калия реабсорбируются в проксимальных извитых канальцах и эта величина не зависит от количества калия, поступающего в организм [4]. В связи с этим калийурез зависит в основном от интенсивности протекания и соотношения процессов реабсорбции и секреции иона в различных отделах нефрона $[2 ; 4 ; 13]$.

Калиевый гомеостаз поддерживается координированным взаимодействием органов и систем, контролируемых нейро-гормональными механизмами, которые обеспечивают процессы временного депонирования избытка катиона, биологически целесообразного рас-
11 Титов В. Н. Натрий плазмы крови // Клиническая лабораторная диагностика. - 1996. - № 3. - С. 3-7. 
пределения его между внутри- и внеклеточными средами организма и экскреции избыточного количества $\mathrm{K}^{+}$преимущественно с мочой $[2 ; 4 ; 13 ; 24 ; 25]$.
Схема регуляции баланса иона калия в организме представлена на рисунке 2.

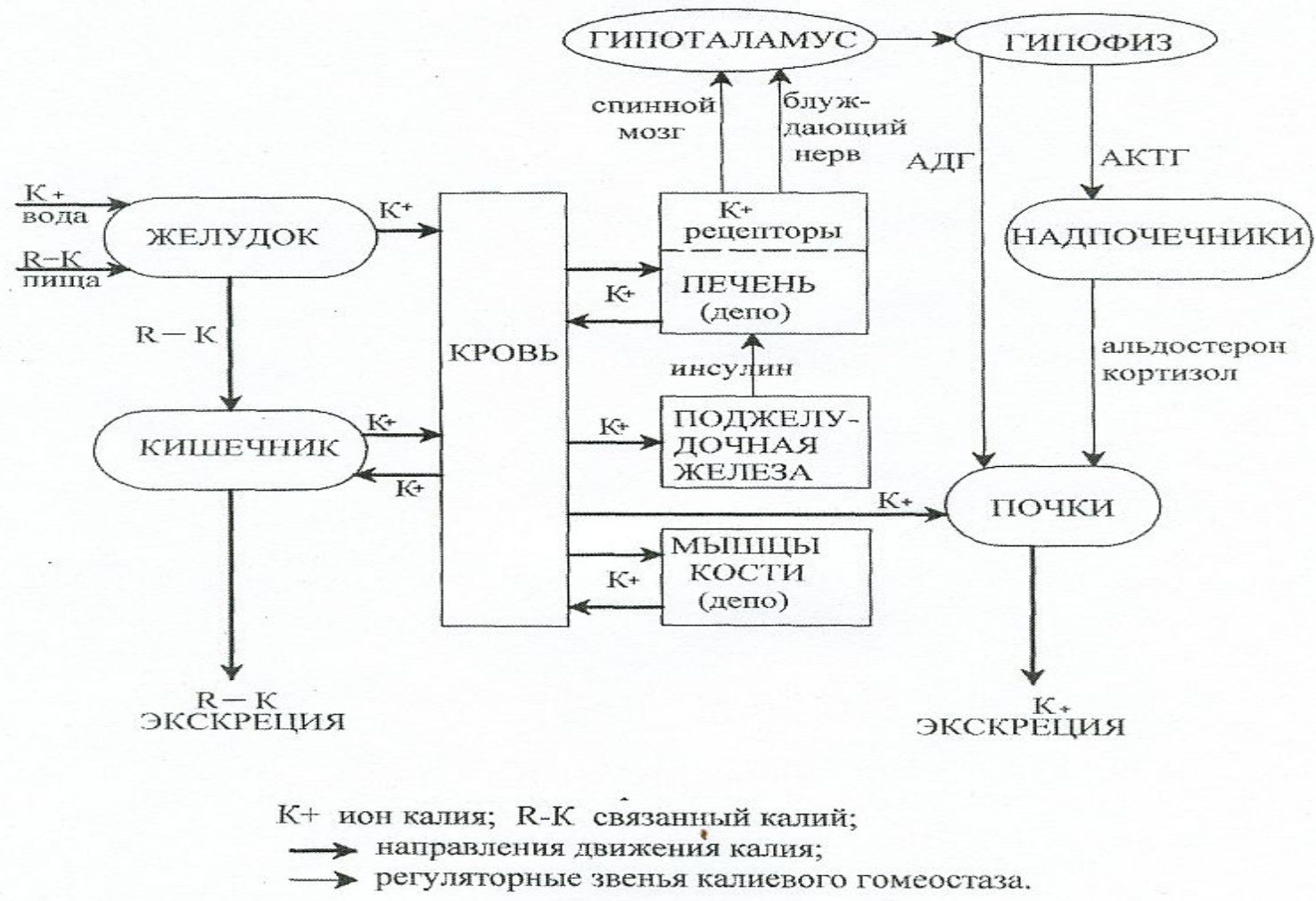

Puc. 2. Схема регуляции баланса иона калия в организме.

Fig. 2. Scheme of ion potassium balance regulation in the organism

Рассмотренные физиологические механизмы регуляции гомеостаза калия послужили основой для гигиенического обоснования его содержания в питьевой воде при длительном eе потреблении. Физиолого-гигиеническое изучение реакций организма на хроническое воздействие $K^{+}$питьевой воды было проведено на беспородных белых крысах самцах в девятимесячном эксперименте со свободным питьевым режимом и стандартным кормле-

\footnotetext{
${ }^{12}$ Красовский Г. Н., Егорова Н. А. Методология выбора оценочных показателей для гигиенического мониторинга водных объектов // Гигиена и санитария. 1994. - № 6. - C. 5-7.
}

нием животных ${ }^{12}$. Питьевая вода имела нормальные органолептические свойства и ионный состав витальных катионов, за исключением иона $K^{+}$. Концентрация калия в контрольной природной питьевой воде состав-

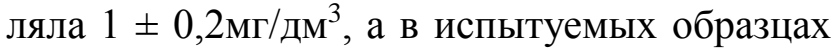
точно моделировалась в концентрациях 5,0 и 50,0 мг/дм ${ }^{3}$. В течение всего эксперимента крысы в контроле и в группах наблюдения (5,0 и 50,0 мг/дм $\left.{ }^{3}\right)$ потребляли одинаковое количество питьевой воды. В течение девяти месяцев 
эксперимента животные опытных и контрольной групп имели одинаковую динамику массы тела ${ }^{13}$.

При анализе кислотно-щелочного равновесия у крыс, получавших питьевую воду с

\section{Показатели кислотно-щелочного равновесия крови у крыс при длительном приеме $\mathbf{K}^{+}$с питьевой водой} тистически значимый сдвиг $р H$ крови и снижение истинного бикарбоната на третьем и пятом месяцах эксперимента (табл. 1).

Таблицุа 1

Table 1

Parameters of blood acid-base balance in rats following prolonged intake of $\mathrm{K}^{+}$with drinking water

\begin{tabular}{|c|c|c|c|}
\hline $\begin{array}{c}\text { Сроки эксперимента, } \\
\text { месяцы }\end{array}$ & $\begin{array}{c}\text { K}^{+} \text {в питьевой воде, } \\
\text { мг } / \text { дм }^{3}\end{array}$ & рН крови & $\begin{array}{c}\text { Истинный бикарбо- } \\
\text { нат мэкв/л }\end{array}$ \\
\hline \multirow{3}{*}{3} & $\begin{array}{c}\text { Контроль } \\
1 \pm 0,2\end{array}$ & $7,41 \pm 0,01$ & $36,58 \pm 2,37$ \\
\hline & 5,0 & $7,41 \pm 0,01$ & $31,42 \pm 1,81$ \\
\hline & 50,0 & $7,44 \pm 0,01 *$ & $30,92 \pm 0,79 *$ \\
\hline \multirow{3}{*}{5} & $\begin{array}{c}\text { Контроль } \\
1 \pm 0,2\end{array}$ & $7,43 \pm 0,01$ & $27,97 \pm 1,35$ \\
\hline & 5,0 & $7,43 \pm 0,01$ & $25,72 \pm 0,62$ \\
\hline & 50,0 & $7,42 \pm 0,01 *$ & $26,27 \pm 0,49$ \\
\hline
\end{tabular}

Примечание. Здесь и в последующих таблицах статистически достоверные значения по сравнению с контролем выделены полужирным и знаком *

Однако сдвиг $p H$ крови не выходил за пределы физиологической нормы и, следовательно, являлся лишь сигналом физиологического адаптационного напряжения механизмов регуляции гомеостаза калия, не имеющих патофизиологического значения. При потреблении питьевой воды, содержащей $K^{+}$в концентрации 50 мг/дм ${ }^{3}$, у животных наблюдалась выраженная тенденция к снижению истинного бикарбоната в крови.
Показатели буферных оснований, сдвига буферных оснований и напряжения угольной кислоты в крови с первого по девятый месяц включительно в опытных и контрольной группах крыс не имели статистических различий (табл. 1). На втором и третьем месяцах эксперимента у крыс наблюдался дисбаланс калийнатриевого равновесия в эритроцитах и плазме крови после приема воды с концентрацией калия 50,0 мг/дм³ (табл. 2).

\footnotetext{
13 Трофимович Е. М., Айзман Р. И., Крашенинина Г. И., Герасев А. Д. Обмен калия и его гигиеническое значение. - Новосибирск: Изд-во НГПУ, 2004. - 40 с.
} 
Вестник Новосибирского государственного педагогического университета

2018, том 8, № 5

www.vestnik.nspu.ru

ISSN 2226-3365

Таблица 2

Концентрация витальных катионов в крови крыс при длительном приеме К ${ }^{+}$с питьевой водой

Concentration of vital cations in blood of rats following prolonged intake of $\mathrm{K}^{+}$with drinking water

\begin{tabular}{|c|c|c|c|c|c|c|c|}
\hline \multirow{3}{*}{$\begin{array}{l}\text { Сроки } \\
\text { экспе- } \\
\text { ри- } \\
\text { мента, } \\
\text { месяц }\end{array}$} & \multirow{3}{*}{$\begin{array}{c}\text { Концен- } \\
\text { трация } \\
\text { калия в } \\
\text { питьевой } \\
\text { воде } \\
\text { мг/дм }\end{array}$} & \multicolumn{6}{|c|}{ Концентрация ионов, ммоль/л } \\
\hline & & \multicolumn{3}{|c|}{ Эритроциты } & \multicolumn{3}{|c|}{ Плазма крови } \\
\hline & & Натрий & Калий & $\mathrm{Na} / \mathrm{K}$ & Натрий & Калий & $\mathrm{Na} / \mathrm{K}$ \\
\hline \multirow{3}{*}{2} & Контроль & $13,68 \pm 0,29$ & $104,5 \pm 2,5$ & $0,13 \pm 0,01$ & $145,1 \pm 3,5$ & $5,53 \pm 0,22$ & $26,2 \pm 0,04$ \\
\hline & 5,0 & $13,68 \pm 0,13$ & $104,2 \pm 0,7$ & $0,13 \pm 0,02$ & $135,7 \pm 4,6$ & $5,35 \pm 0,23$ & $25,4 \pm 0,06$ \\
\hline & 50,0 & $15,58 \pm 0,15^{*}$ & $103,2 \pm 1,3$ & $0,15 \pm 0,01^{*}$ & $138,1 \pm 2,6$ & $5,58 \pm 0,14$ & $24,7 \pm 0,05^{*}$ \\
\hline \multirow{3}{*}{3} & Контроль & $15,88 \pm 1,36$ & $106,7 \pm 0,4$ & $0,15 \pm 0,01$ & $146,9 \pm 3,2$ & $5,25 \pm 0,21$ & $27,9 \pm 0,05$ \\
\hline & 5,0 & $18,67 \pm 2,12$ & $114,5 \pm 3,6$ & $0,16 \pm 0,03$ & $135,2 \pm 7,3$ & $5,21 \pm 0,32$ & $26,0 \pm 0,07$ \\
\hline & 50,0 & $16,63 \pm 1,34$ & $109,6 \pm 4,3$ & $0,15 \pm 0,02$ & $140,0 \pm 2,8$ & $5,59 \pm 0,20$ & $25,0 \pm 0,04^{*}$ \\
\hline
\end{tabular}

С четвертого по девятый месяц эксперимента содержание витальных катионов крови контрольных и опытных животных сохранялось на уровне физиологической нормы.

Функциональное компенсаторное напряжение механизмов регуляции водно-солевого обмена при употреблении питьевой воды с избытком калия выявилось при анализе диуретической и ионоуретической функций почек крыс.

Поскольку в условиях стандартного режима вивария в условиях покоя гидро- и ионноуретическая функции почек между группами экспериментальных животных и контролем не различались, исследование водно-солевого обмена у крыс проводилось с помощью функциональной нагрузочной пробы ${ }^{14}$ - после однократного перорального введения 1\%-го водного раствора $\mathrm{KCl}$ в объеме $3 \%$ от массы тела. Указанная нагрузка соответствовала 1/2-

\footnotetext{
${ }^{14}$ Aizman R. I., Velikanova L. K. Evaluation of water-salt metabolism and kidney function by means of stress tests.
}

1/3 величине суточного приема воды и калия животными в стандартных условиях вивария.

Всасывание воды из пищеварительного тракта и возникающая гипоосмия в портальной системе вызывает возбуждение осморецепторов печени. В результате этого ингибируется секреция АДГ из задней доли гипофиза, что приводит к снижению реабсорбции воды в почечных канальцах и развитию водного диуреза, показателем которого является экскреция осмотически свободной воды, а также снижение экскреции натрия в связи с активацией его реабсорбции в дистальном сегменте нефрона альдостероном [27; 28]. Прием калия вызывает возбуждение калийчувствительных рецепторов печени и включение калийрегулирующего рефлекса, который выражается в увеличении реабсорбции осмотиче-

New methods of scientific research in clinical and experimental medicine. Ed. V. P. Lozovoi. - Novosibirsk, SB AMS USSR, 1980. - Pp. 5-13. 
Вестник Новосибирского государственного педагогического университета

ски свободной воды с одновременным повышением секреции АДГ и альдостерона и увеличением экскреции катионов, преимущественно калия $[2 ; 4 ; 13 ; 14]$.

В таблицах 3 и 4 представлены показатели диуретической и ионоуретической функций почек крыс после пероральной калиевой нагрузки, проводимой на третьем, пятом и девятом месяцах эксперимента.
При использовании функциональной нагрузочной пробы у животных, длительно употреблявших воду с концентрацией калия 50 мг/дм ${ }^{3}$, на девятом месяце наблюдения выявлено, по сравнению с контрольной серией, снижение диуреза и процента выведения жидкости за три часа после нагрузки, вероятно, за счет увеличения ее реабсорбции (экскретируемая фракция жидкости также имела выраженную тенденцию к снижению) (табл. 3).

Таблища 3

Показатели диуретической функции почек у крыс после пероральной водно-калиевой нагрузки

Parameters of diuretic renal function in rats after peroral water-potassium loading

\begin{tabular}{|c|c|c|c|c|c|}
\hline $\begin{array}{c}\text { Сроки } \\
\text { экспери- } \\
\text { мента, в } \\
\text { месяцах }\end{array}$ & $\begin{array}{c}\text { Концен- } \\
\text { трация } \\
\text { калия в } \\
\text { питьевой } \\
\text { воде, } \\
\text { мг/ дм }\end{array}$ & $\begin{array}{c}\text { Диурез (V) } \\
\text { мл/100 г час }\end{array}$ & $\begin{array}{c}\text { \% выведения } \\
\text { водной } \\
\text { нагрузки } \\
\left(B_{\text {H20 }}\right) \text { за } 3 \text { часа }\end{array}$ & $\begin{array}{c}\text { Экскретируе- } \\
\text { мая фракция } \\
\text { жидкости } \\
\left(\text { ЕFН }_{2} \mathrm{O}\right) \\
\%\end{array}$ & $\begin{array}{c}\text { Осмотическое } \\
\text { очищение } \\
\text { (С осм.) } \\
\text { мл / 100г час }\end{array}$ \\
\hline \multirow[t]{3}{*}{3} & контроль & $0,28 \pm 0,03$ & $76,1 \pm 8,7$ & $1,5 \pm 0,10$ & $0,15 \pm 0,01$ \\
\hline & 5 & $0,28 \pm 0,03$ & $74,5 \pm 8,5$ & $1,9 \pm 0,40$ & $0,11 \pm 0,01$ \\
\hline & 50 & $0,31 \pm 0,02$ & $83,5 \pm 6,2$ & $2,3 \pm 0,50$ & $0,15 \pm 0,01$ \\
\hline \multirow[t]{3}{*}{5} & контроль & $0,28 \pm 0,04$ & $73,6 \pm 9,5$ & $1,3 \pm 0,10$ & $0,26 \pm 0,02$ \\
\hline & 5 & $0,22 \pm 0,03$ & $68,5 \pm 7,1$ & $1,1 \pm 0,10$ & $0,27 \pm 0,04$ \\
\hline & 50 & $0,28 \pm 0,02$ & $74,5 \pm 6,2$ & $1,2 \pm 0,06$ & $0,26 \pm 0,03$ \\
\hline \multirow[t]{3}{*}{9} & контроль & $0,28 \pm 0,01$ & $74,8 \pm 3,6$ & $2,3 \pm 0,40$ & $0,22 \pm 0,04$ \\
\hline & 5 & $0,25 \pm 0,05$ & $67,1 \pm 12,4$ & $2,6 \pm 0,45$ & $0,32 \pm 0,04 *$ \\
\hline & 50 & $0,19 \pm 0,03^{*}$ & $50,6 \pm 6,6^{*}$ & $2,0 \pm 0,34$ & $0,54 \pm 0,07 *$ \\
\hline
\end{tabular}

Параллельно возрастало очищение осмотически активных веществ, что заставляло думать об увеличении экскреции ионов. Действительно, параллельно изменению диуреза происходило повышение экскреции ионов натрия и калия с мочой и их экскретируемых фракций по сравнению с контролем (табл. 4).

Увеличение экскретируемых фракций $K^{+}$ и $\mathrm{Na}^{+}$свидетельствовало об уменьшении их реабсорбции в канальцах нефрона вследствие изменения активности гормонального звена регуляции водно-солевого гомеостаза.

Следовательно, при хроническом действии $K^{+}$питьевой воды в концентрации $50 \mathrm{мг} /$ дм $^{3}$ система водно-солевого равновесия отвечала на специфический нагрузочный стимул активацией ионорегулирующих механизмов, направленных на выведение калия при более высокой его концентрации в питьевой воде (табл. 4). 
Вестник Новосибирского государственного педагогического университета

Таблица 4

Показатели ионоуретической функции почек у крыс после пероральной водно-калиевой нагрузки

Parameters of ionuretic renal function in rats after peroral water-potassium loading

\begin{tabular}{|c|c|c|c|c|c|}
\hline $\begin{array}{c}\text { Сроки } \\
\text { экспери- } \\
\text { мента, в } \\
\text { месяцах }\end{array}$ & $\begin{array}{c}\text { Концентрация } \\
\text { калия в питье- } \\
\text { вой воде, } \\
\text { мг/ дм }{ }^{3}\end{array}$ & $\begin{array}{c}\text { Экскреция } \\
\text { натрия } \\
\left(\mathrm{U}_{\mathrm{Na}} \cdot \mathrm{V}\right) \\
\text { мкмоль / } \\
100 \text { ч час }\end{array}$ & $\begin{array}{c}\text { Экскретируе- } \\
\text { мая фракция } \\
\text { натрия } \\
\left(\text { EF }_{\mathrm{Na}}\right) \\
\%\end{array}$ & $\begin{array}{c}\text { Экскреция калия } \\
\left(\mathrm{U}_{\mathrm{K}} \cdot \mathrm{V}\right) \\
\text { мкмоль } / \\
100 \text { г час }\end{array}$ & $\begin{array}{c}\text { Экскретируе- } \\
\text { мая фракция } \\
\text { калия } \\
\left(\mathrm{EF}_{\mathrm{K}}\right) \\
\%\end{array}$ \\
\hline \multirow[t]{3}{*}{3} & контроль & $5,11 \pm 1,1$ & $0,09 \pm 0,02$ & $35,1 \pm 3,6$ & $4,29 \pm 0,84$ \\
\hline & 5,0 & $6,93 \pm 1,3$ & $0,11 \pm 0,03$ & $29,5 \pm 4,2$ & $5,36 \pm 0,86$ \\
\hline & 50,0 & $7,41 \pm 1,2$ & $0,07 \pm 0,02$ & $36,2 \pm 2,8$ & $3,70 \pm 0,96$ \\
\hline \multirow[t]{3}{*}{5} & контроль & $6,60 \pm 2,0$ & $0,46 \pm 0,1$ & $34,5 \pm 3,4$ & $2,20 \pm 0,25$ \\
\hline & 5,0 & $3,60 \pm 0,9$ & $0,43 \pm 0,1$ & $26,4 \pm 4,3$ & $3,03 \pm 0,84$ \\
\hline & 50,0 & $4,19 \pm 0,5$ & $0,32 \pm 0,08$ & $34,4 \pm 2,7$ & $2,08 \pm 0,29$ \\
\hline \multirow[t]{3}{*}{9} & контроль & $7,29 \pm 0,7$ & $0,06 \pm 0,01$ & $28,5 \pm 1,8$ & $4,21 \pm 1,86$ \\
\hline & 5,0 & $7,27 \pm 1,8$ & $0,15 \pm 0,05$ & $23,4 \pm 3,7$ & $4,06 \pm 0,1$ \\
\hline & 50,0 & $8,78 \pm 0,1^{*}$ & $0,18 \pm 0,04^{*}$ & $40,3 \pm 2,1^{*}$ & $10,10 \pm 2,17^{*}$ \\
\hline
\end{tabular}

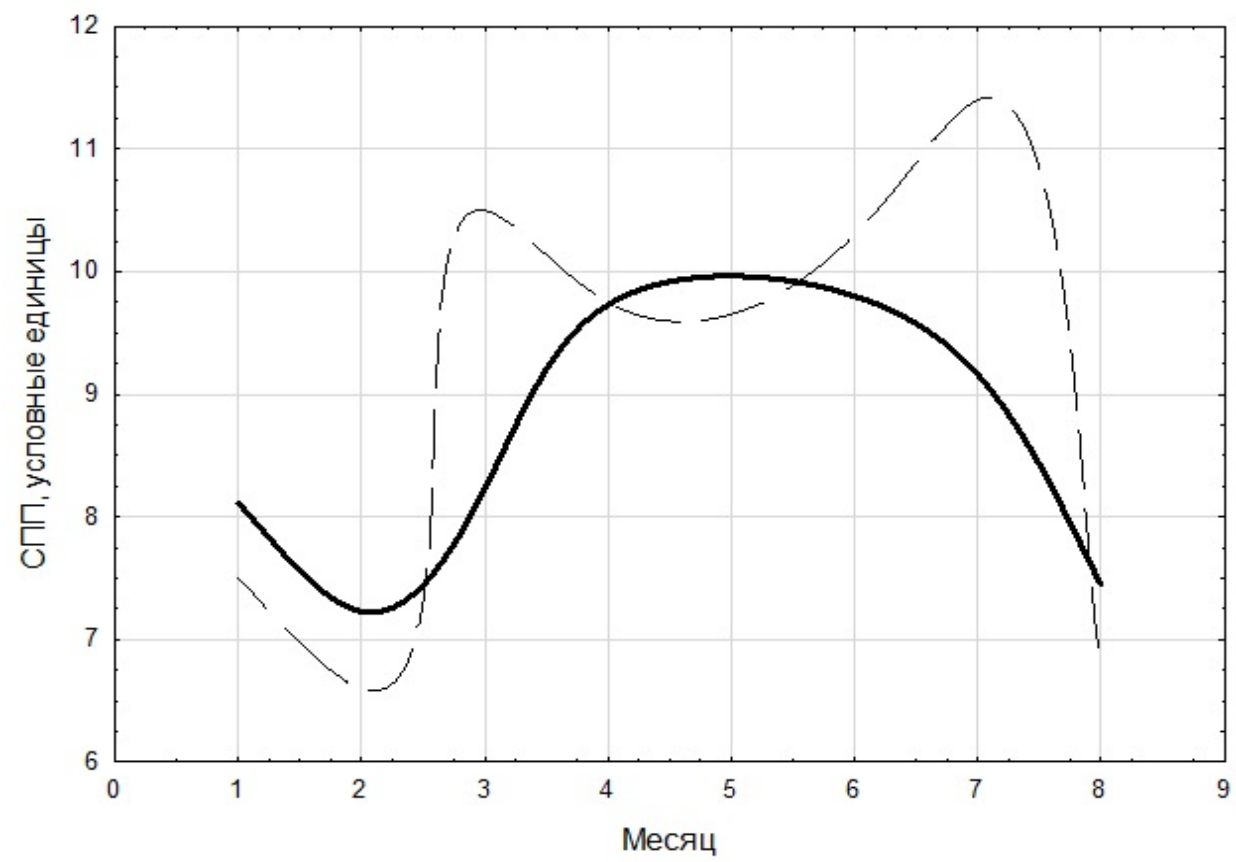

$$
\text { — контроль }\left(1 \mathrm{Mг} / \text { дм }^{3}\right) \quad--->50 \mathrm{мг} / \text { дм }^{3}
$$

Puc. 3. Динамика суммарно-порогового параметра у крыс при длительном приеме иона калия с питьевой водой

Fig. 3. Dynamics of sum-threshold parameter in rats following prolonged intake of $\mathrm{K}^{+}$ion with drinking water 
Вестник Новосибирского государственного педагогического университета

Описанные изменения почечной реакции на калиевую нагрузку у крыс, длительно получавших питьевую воду с концентрацией калия 50 мг/дм³ вероятно обусловлены функциональными сдвигами как в центральном, так и эфферентном звеньях регуляции калиевого гомеостаза (гипоталамус-гипофиз надпочечники - почки), на что указывает изменение реабсорбционных процессов в почках, активность которых регулируется нейрогормональными механизмами [2; 13; 14]. Действительно, хроническое поступление $K^{+}$с питьевой водой в концентрации 50 мг/дм ${ }^{3}$ привело к разбалансированию процессов возбуждения и торможения в центральной нервной системе. У крыс в начале и конце опыта возбудимость нервных центров имела тенденцию к повышению по тесту суммарно-порогового показателя (СПП) болевого рефлекса (рис. 3).
В эксперименте с применением метода «открытого поля» исследовалась поведенческая активность крыс путём определения их горизонтальной активности (число пересечений квадратов поля), вертикальной активности (число вставаний на задние лапки), исследовательской активности (частота заглядываний в норки) и суммарная двигательная активность. Снижение основных видов двигательной активности было зарегистрировано только у крыс, получавших питьевую воду, содержащую $K^{+}$в концентрации 50 мг/дм ${ }^{3}$, что вероятно обусловлено разбалансированием возбудительных и тормозных процессов в центральной нервной системе за счет длительного избыточного поступленния калия с питьевой водой (табл. 5).

Таблицุа 5

\section{Динамика поведения экспериментальных животных в «открытом поле» в хроническом} эксперименте

Dynamics of activity of experimental animals in "open field" chronic experiment

\begin{tabular}{|c|c|c|c|c|}
\hline \multirow{2}{*}{ Показатель } & \multirow[t]{2}{*}{ Mec. } & \multicolumn{3}{|c|}{ Концентрация калия в питьевой воде, мг/дм³ } \\
\hline & & контроль & 5,0 & 50,0 \\
\hline \multirow{3}{*}{$\begin{array}{c}\text { Горизонтальная актив- } \\
\text { ность }\end{array}$} & 5 & $18,21 \pm 2,17$ & $18,75 \pm 5,49$ & $9,24 \pm 2,39 *$ \\
\hline & 7 & $21,23 \pm 2,42$ & $16,38 \pm 2,65$ & $7,31 \pm 1,95^{*}$ \\
\hline & 8 & $19,58 \pm 3,09$ & $12,54 \pm 1,86$ & $7,80 \pm 1,33^{*}$ \\
\hline \multirow[t]{3}{*}{ Вертикальная активность } & 5 & $5,31 \pm 0,83$ & $2,80 \pm 0,50 *$ & $3,04 \pm 0,62^{*}$ \\
\hline & 7 & $4,46 \pm 0,52$ & $3,54 \pm 0,53$ & $2,02 \pm 0,62^{*}$ \\
\hline & 8 & $4,03 \pm 0,62$ & $2,73 \pm 0,41$ & $1,61 \pm 0,26^{*}$ \\
\hline \multirow{3}{*}{$\begin{array}{c}\text { Исследовательская актив- } \\
\text { ность }\end{array}$} & 5 & $1,14 \pm 0,25$ & $1,75 \pm 0,26$ & $0,58 \pm 0,18$ \\
\hline & 7 & $3,07 \pm 1,08$ & $1,08 \pm 0,26$ & $0,83 \pm 0,18$ \\
\hline & 8 & $1,67 \pm 0,84$ & $0,83 \pm 0,26$ & $1,03 \pm 0,26$ \\
\hline \multirow{3}{*}{$\begin{array}{c}\text { Суммарная двигательная } \\
\text { активность }\end{array}$} & 5 & $8,26 \pm 1,08$ & $7,77 \pm 2,06$ & $4,25 \pm 1,06^{*}$ \\
\hline & 7 & $9,56 \pm 1,33$ & $7,01 \pm 1,15$ & $3,39 \pm 0,92^{*}$ \\
\hline & 8 & $8,42 \pm 1,58$ & $5,35 \pm 0,88$ & $3,47 \pm 0,62 *$ \\
\hline \multirow[t]{3}{*}{ Груминговые реакции } & 5 & $2.15 \pm 0,42$ & $1,83 \pm 0,44$ & $1,75 \pm 0,53$ \\
\hline & 7 & $2,54 \pm 0,83$ & $2,16 \pm 0,62$ & $1,42 \pm 0,35$ \\
\hline & 8 & $2,75 \pm 0,44$ & $2,17 \pm 0,53$ & $1,50 \pm 0,35^{*}$ \\
\hline
\end{tabular}


При концентрации в питьевой воде иона калия от $1 \pm 0,2$ до 5 мг/дм ${ }^{3}$ изменений в системе регуляции калиевого гомеостаза и со стороны ЦНС не было обнаружено.

Таким образом, можно заключить, что оптимум гигиенической нормы (ОГН) калия в питьевой воде составляет 1-5 мг/дм ${ }^{3}$. Контрольная группа животных в течение девяти месяцев получала питьевую воду с сезонными колебаниями концентрации $K^{+} 08-1,2$ мг/дм ${ }^{3}$, поэтому нижняя граница допустимой гигиенической нормы (ДГН) калия составляет 0,8 мг/дм³. Верхняя граница ДГН калия находится между верхней границей ОГН 5 мг/дм ${ }^{3}$ и концентрацией $K^{+} 50$ мг/дм ${ }^{3}$. В математической статистике сущностный анализ эффективных значений признаков оптимален в их диапазоне 20-75 \%, а в санитарной токсикологии диапазон линейной зависимости действующих концентраций абсолютно реален в интервале 16-84 \% недостающей последовательности эффектов ${ }^{16}$, поэтому в интервале концентраций калия 5-50 мг/дм³ в питьевой воде предельный допустимый уровень неэффективной концентрации $K^{+}\left(\mathrm{EC}_{16}\right)$ составляет 7,2 мг/дм ${ }^{3}$. Следовательно, верхняя граница допустимой гигиенической нормы калия в питьевой воде составляет $5+7,2=12,2 \mathrm{мг} /$ дм $^{3}$, или округленно с учетом гигиенической надежности 12,5 мг/дм³. Эта концентрация практически полностью совпадает с нормой предельного содержания калия 12,0 мг/дм³ установленной для питьевой воды в Европейском сообществе директивой 98/83ЕС «По качеству питьевой воды, предназначенной для потребления человеком».

\section{Заключение}

Представленные в статье современные данные о механизмах осмо- и ионорегуляции (в частности, регуляции гомеостаза калия) позволили дать теоретическое обоснование физиолого-гигиеническим исследованиям по изучению влияния различных концентраций катиона в питьевой воде на функции почек и состояние центральной нервной системы, на основании чего был экспериментально определен диапазон допустимой гигиенической нормы калия в питьевой воде (ДГН), который не вызывал нарушений гомеостаза катиона и механизмов его регуляции при хроническом действии на организм. Этот диапазон составил 0,812,5 мг/дм ${ }^{3}$, тогда как оптимум гигиенической нормы (ОГН) калия в питьевой воде составил 1-5 мг/дм³. Данный методологический подход к обоснованию ДГН и ОГН различных ионов в питьевой воде может быть использован в теоретических и прикладных работах, а также в учебных заданиях.

\section{СПИСОК ЛИТЕРАТУРЫ}

1. Aizman R., Grahnquist L., Celsi G. Potassium homeostasis: ontogenic aspects // Acta Pediatrica. 1998. - Vol. 87, Issue 6. - P. 609-617. DOI: https://doi.org/10.1080/080352598750013987

2. Айзман Р. И. Регуляция гомеостаза калия: возрастные особенности // Нефрология и диализ. 2001. - T. 3, № 3. - C. 318-325. URL: https://elibrary.ru/item.asp?id=24766806

\footnotetext{
${ }^{15}$ Красовский Г. Н., Егорова Н. А. Методология выбора оценочных показателей для гигиенического мониторинга водных объектов // Гигиена и санитария. 1994. - № 6. - C. 5-7.
} 
3. Sun H., Sun M. Age- and gender-dependent associations of blood pressure and serum sodium and potassium-renal and extrarenal regulations // Journal of the American Society of Hypertension. 2018. - Vol. 12, Issue 5. - P. 392-401. DOI: https://doi.org/10.1016/j.jash.2018.03.005

4. Palmer B. F. Regulation of Potassium Homeostasis // Clinical Journal of the American Society of Nephrology. - 2015. - Vol. 10, Issue 6. - P. 1050-1060. DOI: https://doi.org/10.2215/CJN.08580813

5. Rodan A. R. Potassium: Friend or Foe? // Pediatric Nephrology. - 2017. - Vol. 32, Issue 7. P. 1109-1121. DOI: https://doi.org/10.1007/s00467-016-3411-8

6. Leurs L. J., Schouten L. J., Mons M. N., Goldbohm R. A., van den Brandt P. A. Relationship between tap water hardness, magnesium and calcium concentration and mortality due to ischemic heart disease or stroke in The Netherlands // Environmental Health Perspective. - 2010. - Vol. 118, № 3. - P. 414-420. DOI: https://doi.org/10.1289/ehp.0900782

7. Talukder M. R. R., Rutherford S., Huang C., Phung D., Islam M. Z., Chu C. Drinking water salinity and risk of hypertension: A systematic review and meta-analysis // Archives of Environmental and Occupational Health. - 2017. - Vol. 72, Issue 3. - P. 126-138. DOI: https://doi.org/10.1080/19338244.2016.1175413

8. Talukder M. R. R., Rutherford S., Phung D., Islam M. Z., Chu C. The effect of drinking water salinity on blood pressure in young adults of coastal Bangladesh // Environmental Pollution. 2016. - Vol. 214. - P. 248-254. DOI: https://doi.org/10.1016/j.envpol.2016.03.074

9. Rylander R. Magnesium in drinking water - a case for prevention? // Journal of Water and Health. 2013. - Vol. 12, № 1. - P. 34-40. DOI: https://doi.org/10.2166/wh.2013.110

10. Davies B. E. The UK geochemical environment and cardiovascular diseases: magnesium in food and water // Environmental Geochemistry and Health. - 2015. - Vol. 37, Issue 3. - P. 411-427. DOI: https://doi.org/10.1007/s10653-014-9671-y

11. Gianfredi V., Bragazzi N. L., Nucci D., Villarini M., Moretti M. Cardiovascular diseases and hard drinking waters: from a systematic review with meta-analysis of case-control studies // Journal of Water and Health. - 2016. - Vol. 15, Issue 1. - P. 31-40. DOI: https://doi.org/10.2166/wh.2016.131

12. Şener Ş., Şener E., Davraz A. Assessment of groundwater quality and health risk indrinking water basin using GIS // Journal of Water and Health. - 2016. - Vol. 15, Issue 1. - P. 112-132. DOI: https://doi.org/10.2166/wh.2016.148

13. Youn J. H., McDonough A. A. Recent Advances in Understanding Integrative Control of Potassium Homeostasis // Annual Review of Physiology. - 2009. - Vol. 71. - P. 381-401. DOI: https://doi.org/10.1146/annurev.physiol.010908.163241

14. Rabinowitz L., Aizman R. I. The Central Nervous System in Potassium Homeostasis // Frontiers in Neuroendocrinology. - 1993. - Vol. 14, Issue 1. - P. 1-26. DOI: https://doi.org/10.1006/frne.1993.1001

15. Боровец Е. Н., Айзман Р. И. Возрастные особенности транспорта калия в дистальном отделе толстой кишки крыс // Нефрология и диализ. - 2003. - Т. 5, № 3. - С. 226-227. URL: https://elibrary.ru/item.asp?id=25523669

16. Youn J. H. Gut sensing of potassium intake and its role in potassium homeostasis // Seminars in Nephrology. - 2013. - Vol. 33, Issue 3. - P. 248-256. DOI: https://doi.org/10.1016/j.semnephrol.2013.04.005

17. Garty H., Karlish S. J. D. Role of FXYD proteins in ion transport // Annual Review of Physiology. 2006. - Vol. 68. - P. 431-459. DOI: https://doi.org/10.1146/annurev.physiol.68.040104.131852 
18. Garty H., Lindzen M., Scanzano R., Aizman R., Füzesi M., Goldshleger R., Farman N., Blostein R., Karlish S. J. D. A functional interaction between CHIF and Na-K-ATPase: implication for regulation by FXYD proteins // American Journal of Physiology. Renal Physiology. 2002. - Vol. 283, Issue 4. - P. F607-F615. DOI: https://doi.org/10.1152/ajprenal.00112.2002

19. Rabinowitz L. Aldosterone and potassium homeostasis // Kidney International. - 1996. - Vol. 49, Issue 6. - P. 1738-1742. DOI: https://doi.org/10.1038/ki.1996.258

20. DuBose Jr. T. D. Regulation of Potassium Homeostasis in CKD // Advances in Chronic Kidney Disease. - 2017. - Vol. 24, Issue 5. - P. 305-314. DOI: https://doi.org/10.1053/j.ackd.2017.06.002

21. Gilligan S., Raphael K. L. Hyperkalemia and Hypokalemia in CKD: Prevalence, Risk Factors, and Clinical Outcomes // Advances in Chronic Kidney Disease. - 2017. - Vol. 24, Issue 5. P. 315-318. DOI: https://doi.org/10.1053/j.ackd.2017.06.004

22. Geibel J. P. Role of potassium in acid secretion // World Journal of Gastroenterology. - 2005. Vol. 11 (34). $\quad-\quad$ P. 5259-5265. PMCID: PMC4622792 DOI: https://doi.org/10.3748/wjg.v11.i34.5259

23. Arin R. M., Gorostidi A., Navarro-Imaz H., Rueda Y., Fresnedo O., Ochoa B. Adenosine: Direct and Indirect Actions on Gastric Acid Secretion // Frontiers in Physiology. - 2017. - Vol. 8. P. 737. DOI: https://doi.org/10.3389/fphys.2017.00737

24. Елькова Н. Г., Айзман Р. И. Возрастные изменения содержания воды и электролитов в тканях // Новые исследования по возрастной физиологии. - 1988. - № 1. - С. 35-39. URL: https://elibrary.ru/item.asp?id=26097260

25. Финкинштейн Я. Д., Айзман Р. И., Тернер А. Я., Пантюхин И. В. Рефлекторный механизм регуляции калиевого гомеостаза // Физиологический журнал СССР им. И. М. Сеченова. - 1973. - Т. 59, № 9. - С. 1429-1436. URL: https://elibrary.ru/item.asp?id=26097780

26. Aizman R. I., Subotyalov M. A. Formation and Development of Scientific views about Physiology of Kidneys and Water-Balance in Novosibirsk // MOJ Anatomy and Physiology. 2017. - Vol. 4 (3). - P. 308-309. DOI: https://doi.org/10.15406/mojap.2017.04.00136

27. Айзман Р. И., Финкинштейн Я. Д. Осмо- и ионные рецепторы печени // Физиологический журнал СССР им. И. М. Сеченова. - 1976. - Т. 62, № 1. - С. 128-136. URL: https://elibrary.ru/item.asp?id=26097680

28. Bourque C. W., Oliet S. H. R., Richard D. Osmoreceptors, osmoreception, and osmoregulation // Frontiers in Neuroendocrinology. - 1994. - Vol. 15, Issue 3. - P. 231-274. DOI: https://doi.org/10.1006/frne.1994.1010 
DOI: $10.15293 / 2226-3365.1805 .16$

Roman Idelevich Aizman,

Doctor of Biological Sciences, Professor, Head,

Department of Anatomy, Physiology and Life Safety,

Novosibirsk State Pedagogical University;

Leading Researcher,

Novosibirsk Research Institute of Hygiene Rospotrebnadzor, Novosibirsk,

Russian Federation.

ORCID ID: http://orcid.org/0000-0002-7776-4768

E-mail: aizman.roman@yandex.ru

Alexey Dmitrievich Gerasev,

Doctor of Biological Sciences, Professor, Rector,

Novosibirsk State Pedagogical University, Novosibirsk, Russian Federation.

ORCID ID: http://orcid.org/0000-0002-6442-3956

E-mail: ad-gerasev@yandex.ru

Oleg Aizman,

Ph.D., M.D.,

Department of Anesthesiology and Intensive Care,

Karolinska Institute, Stockholm, Sweden

E-mail: oleg.aizman@karolinska.se

Galina Ivanovna Krasheninina,

Doctor of Medical Sciences, Professor,

Department of Hygiene and Ecology,

Novosibirsk State Medical University;

Leading Researcher,

Novosibirsk Research Institute of Hygiene Rospotrebnadzor, Novosibirsk, Russian Federation.

ORCID ID: http://orcid.org/0000-0002-8419-744X

E-mail: ngi@niig.su

Evgeny Mikhaylovich Trofimovich,

Doctor of Medical Sciences, Professor,

Department of Anatomy, Physiology and Life Safety,

Novosibirsk State Pedagogical University, Novosibirsk, Russian Federation.

ORCID ID: http://orcid.org/0000-0003-2086-6357

E-mail:aph@nspu.ru

\section{Physiological and hygienic basis of potassium norm in drinking water: Theoretical and practical implications}

\section{Abstract}

Introduction. Recently there have not been physiological and hygienic investigations aimed at testing and clarifying optimal $(\mathrm{OHN})$ and permissible ( $\mathrm{PHN}$ ) hygienic norms of potassium concentration in drinking water. The potassium concentration standard for drinking water of $12 \mathrm{mg} / \mathrm{dm} 3$, established by the European Community directive 98 / 83EC, has not been empirically investigated. Therefore, teaching this topic in the sections "Physiology of water-salt balance" and "Water supply hygiene" is 
not properly grounded. The aim of this work is to consider the physiology of potassium metabolism in the body and to experimentally justify hygienic norms of potassium concentrations in drinking water.

Materials and Methods. To justify the hygienic norm of potassium content in drinking water, a physiological and hygienic approach based on the theoretical and experimental study of potassium homeostasis in the body of higher animals and humans, as well as on the analysis of physiological responses of the body to long-term dose-dependent effects of potassium loads was used. This made it possible to integrate the results of the study into the system of standards for this cation in drinking water. This physiological and hygienic approach to solving the problem became possible due to the long-term cooperation of researchers from Novosibirsk State Pedagogical University and Hygienic Research Institute, whose scientific developments in the field of physiology of potassium homeostasis regulation and water supply hygiene have received worldwide recognition.

Results. It is shown, that regulation of potassium balance is provided as a direct influence of cation surplus on kidneys in the case of hyperkalemia, and the reflex mechanism which comes into action when potassium is absorbed from the digestive tract. This conclusion is based on the experimental data which prove that potassium-regulating reflex is presented by liver selective receptors, afferent vagal nerve pathways, the hypothalamic centres and hormones (renin-angiotensin-aldosterone system, vasopressin, insulin), causing changes in kidney functions - the main homeostatic organ, and potassium depot in tissues (skeletal muscles and liver).

The second part describes the results of a 9-month chronic experiment in rats receiving drinking water with different potassium concentrations and its effect on kidney functions. It is shown, that potassium concentration of $5,0 \mathrm{mg} / \mathrm{dm}^{3}$ in drinking water did not cause changes in the renal response on water and potassium loadings in comparison with the control group (potassium concentration in drinking water was 1,0 $\pm 0,2 \mathrm{mg} / \mathrm{dm}^{3}$ ), whereas water with the potassium concentration of $50 \mathrm{mg} / \mathrm{dm}^{3}$ led to pressure of ionic balance regulation mechanisms in comparison with the control group. It was expressed in increase of potassium and sodium excretion after water loading and their decrease after potassium loading.

Conclusions. The obtained data allow to conclude that a hygienic optimum of potassium ion concentration in drinking water is $1-5 \mathrm{mg} / \mathrm{dm}^{3}$, the threshold dose causing functional pressure of potassium regulation mechanisms is $50 \mathrm{mg} / \mathrm{dm}^{3}$, and the acceptable hygienic range of potassium in drinking water is $0,8-12,5 \mathrm{mg} / \mathrm{dm}^{3}$.

Keywords

Potassium homeostasis regulation; Kidney function; Potassium loadings; Potassium concentration in drinking water.

\section{REFERENCES}

1. Aizman R., Grahnquist L., Celsi G. Potassium homeostasis: ontogenic aspects. Acta Pediatrica, 1998, vol. 87, issue 6, pp. 609-617. DOI: https://doi.org/10.1080/080352598750013987

2. Aizman R. I. Regulation of potassium homeostasis: age-specific features. Nephrology and Dialysis, 2001, vol. 3, no. 3, pp. 318-325. (In Russian) URL: https://elibrary.ru/item.asp?id=24766806

3. Sun H., Sun M. Age- and gender-dependent associations of blood pressure and serum sodium and potassium-renal and extrarenal regulations. Journal of the American Society of Hypertension, 2018, vol. 12, issue 5, pp. 392-401. DOI: https://doi.org/10.1016/j.jash.2018.03.005

4. Palmer B. F. Regulation of potassium homeostasis. Clinical Journal of the American Society of Nephrology, 2015, vol. 10, issue 6, pp. 1050-1060. DOI: https://doi.org/10.2215/CJN.08580813

5. Rodan A. R. Potassium: Friend or foe?. Pediatric Nephrology, 2017, vol. 32, issue 7, pp. 11091121. DOI: https://doi.org/10.1007/s00467-016-3411-8 
6. Leurs L. J., Schouten L. J., Mons M. N., Goldbohm R. A., van den Brandt P. A. Relationship between tap water hardness, magnesium and calcium concentration and mortality due to ischemic heart disease or stroke in the Netherlands. Environmental Health Perspective, 2010, vol. 118, no. 3, pp. 414-420. DOI: https://doi.org/10.1289/ehp.0900782

7. Talukder M. R. R., Rutherford S., Huang C., Phung D., Islam M. Z., Chu C. Drinking water salinity and risk of hypertension: A systematic review and meta-analysis. Archives of Environmental and Occupational Health, 2017, vol. 72, issue 3, pp. 126-138. DOI: https://doi.org/10.1080/19338244.2016.1175413

8. Talukder M. R. R., Rutherford S., Phung D., Islam M. Z., Chu C. The effect of drinking water salinity on blood pressure in young adults of coastal Bangladesh. Environmental Pollution, 2016, vol. 214, pp. 248-254. DOI: https://doi.org/10.1016/j.envpol.2016.03.074

9. Rylander R. Magnesium in drinking water - a case for prevention?. Journal of Water and Health, 2013, vol. 12, no. 1, pp. 34-40. DOI: https://doi.org/10.2166/wh.2013.110

10. Davies B. E. The UK geochemical environment and cardiovascular diseases: magnesium in food and water. Environmental Geochemistry and Health, 2015, vol. 37, issue 3, pp. 411-427. DOI: https://doi.org/10.1007/s10653-014-9671-y

11. Gianfredi V., Bragazzi N. L., Nucci D., Villarini M., Moretti M. Cardiovascular diseases and hard drinking waters: From a systematic review with meta-analysis of case-control studies. Journal of Water and Health, 2016, vol. 15, issue 1, pp. 31-40. DOI: https://doi.org/10.2166/wh.2016.131

12. Şener Ş., Şener E., Davraz A. Assessment of groundwater quality and health risk indrinking water basin using GIS. Journal of Water and Health, 2016, vol. 15, issue 1, pp. 112-132. DOI: https://doi.org/10.2166/wh.2016.148

13. Youn J. H., McDonough A. A. Recent advances in understanding integrative control of potassium homeostasis. Annual Review of Physiology, 2009, vol. 71, pp. 381-401. DOI: https://doi.org/10.1146/annurev.physiol.010908.163241

14. Rabinowitz L., Aizman R. I. The central nervous system in potassium homeostasis. Frontiers in Neuroendocrinology, 1993, vol. 14, issue 1, pp. 1-26. DOI: https://doi.org/10.1006/frne.1993.1001

15. Borovets E. N., Aizman R. I. Age features of potassium transport in the distal colon of rats. Nephrology and Dialysis, 2003, vol. 5, no. 3, pp. 226-227. (In Russian) URL: https://elibrary.ru/item.asp?id=25523669

16. Youn J. H. Gut sensing of potassium intake and its role in potassium homeostasis. Seminars in Nephrology, 2013, vol. 33, issue 3, pp. 248-256. DOI: https://doi.org/10.1016/j.semnephrol.2013.04.005

17. Garty H., Karlish S. J. D. Role of FXYD proteins in ion transport. Annual Review of Physiology, 2006, vol. 68, pp. 431-459. DOI: https://doi.org/10.1146/annurev.physiol.68.040104.131852

18. Garty H., Lindzen M., Scanzano R., Aizman R., Füzesi M., Goldshleger R., Farman N., Blostein R., Karlish S. J. D. A functional interaction between CHIF and Na-K-ATPase: Implication for regulation by FXYD proteins. American Journal of Physiology. Renal Physiology, 2002, vol. 283, issue 4, pp. F607-F615. DOI: https://doi.org/10.1152/ajprenal.00112.2002

19. Rabinowitz L. Aldosterone and potassium homeostasis. Kidney International, 1996, vol. 49, issue 6, pp. 1738-1742. DOI: https://doi.org/10.1038/ki.1996.258

20. DuBose Jr. T. D. Regulation of potassium homeostasis in CKD. Advances in Chronic Kidney Disease, 2017, vol. 24, issue 5, pp. 305-314. DOI: https://doi.org/10.1053/j.ackd.2017.06.002

21. Gilligan S., Raphael K. L. Hyperkalemia and hypokalemia in CKD: Prevalence, risk factors, and clinical outcomes. Advances in Chronic Kidney Disease, 2017, vol. 24, issue 5, pp. 315-318. DOI: https://doi.org/10.1053/j.ackd.2017.06.004 
22. Geibel J. P. Role of potassium in acid secretion. World Journal of Gastroenterology, 2005, vol. 11, pp. 5259-5265. PMCID: PMC4622792 DOI https://doi.org/10.3748/wjg.v11.i34.5259

23. Arin R. M., Gorostidi A., Navarro-Imaz H., Rueda Y., Fresnedo O., Ochoa B. Adenosine: Direct and indirect actions on gastric acid secretion. Frontiers in Physiology, 2017, vol. 8, pp. 737. DOI: https://doi.org/10.3389/fphys.2017.00737

24. Elkova N. G., Aizman R. I. Age changes in water and electrolyte content in tissues. New Research on Age Physiology, 1988, no. 1, pp. 35-39. (In Russian) URL: https://elibrary.ru/item.asp?id=26097260

25. Finkinshtein Ya. D., Aizman R. I., Terner A. Ya., Pantuhin I. V. Reflex mechanism of potassium homeostasis regulation. Sechenov Physiological Journal of the USSR, 1973, vol. 59, no. 9, pp. 14291436. (In Russian) URL: https://elibrary.ru/item.asp?id=26097780

26. Aizman R. I., Subotyalov M. A. Formation and development of scientific views about physiology of kidneys and water-balance in Novosibirsk. MOJ Anatomy and Physiology, 2017, vol. 4 (3), pp. 308-309. DOI: https://doi.org/10.15406/mojap.2017.04.00136

27. Aizman R. I., Finkinshtein Ya. D. Osmo- and ionic liver receptors. Sechenov Physiological Journal of the USSR, 1976, vol. 62, no. 1, pp. 128-136. (In Russian) URL: https://elibrary.ru/item.asp?id=26097680

28. Bourque C. W., Oliet S. H. R., Richard D. Osmoreceptors, osmoreception, and osmoregulation. Frontiers in Neuroendocrinology, 1994, vol. 15, issue 3, pp. 231-274. DOI: https://doi.org/10.1006/frne.1994.1010 